\title{
An empirical model of optical and radiative characteristics of the tropospheric aerosol over West Siberia in summer
}

\author{
M. V. Panchenko, T. B. Zhuravleva, S. A. Terpugova, V. V. Polkin, and V. S. Kozlov \\ V. E. Zuev Institute of Atmospheric Optics SB RAS, Tomsk, Russia
}

Correspondence to: T. B. Zhuravleva (ztb@iao.ru)

Received: 30 September 2011 - Published in Atmos. Meas. Tech. Discuss.: 5 January 2012

Revised: 4 June 2012 - Accepted: 4 June 2012 - Published: 2 July 2012

\begin{abstract}
An empirical model of the vertical profiles of aerosol optical characteristics is described. This model was developed based on data acquired from multi-year airborne sensing of optical and microphysical characteristics of the tropospheric aerosol over West Siberia. The main initial characteristics for the creation of the model were measurement data of the vertical profiles of the aerosol angular scattering coefficients in the visible wavelength range, particle size distribution functions and mass concentrations of black carbon (BC). The proposed model allows us to retrieve the aerosol optical and radiative characteristics in the visible and near-IR wavelength range, using the season, air mass type and time of day as input parameters. The columnar single scattering albedo and asymmetry factor of the aerosol scattering phase function, calculated using the average vertical profiles, are in good agreement with data from the AERONET station located in Tomsk.

For solar radiative flux calculations, this empirical model has been tested for typical summer conditions. The available experimental database obtained for the regional features of West Siberia and the model developed on this basis are shown to be sufficient for performing these calculations.
\end{abstract}

\section{Introduction}

Research over the past few years has led to the generally accepted conclusion that atmospheric aerosol is one of the main substances determining climate characteristics (IPCC, 2007). Aerosol affects the radiative budget both directly and indirectly. The direct effect is caused by the ability of aerosol particles to scatter and absorb solar and thermal radiation (Haywood and Boucher, 2000), the indirect effect is related to aerosol influence on cloud microstructure, cloud formation processes and precipitation (Albrecht, 1989; Johnson et al., 2004; Twomey, 1977; Ivlev, 2011). The key optical properties of aerosol that determine its radiative effects are the aerosol optical depth, the single scattering albedo and the aerosol scattering phase function/asymmetry factor (Takemura et al., 2002; Yu et al., 2006; Zhou et al., 2006).

Given the wide range of sources, sinks and chemical composition of atmospheric aerosol and the spatial and temporal variations in its properties, it is clear that the most reliable data on aerosol optical characteristics and their transformation under geophysical processes can be obtained only through a detailed comparison of experimental and theoretical studies. This is especially important in terms of calculations performed for particular regional conditions.

Regular measurements carried out over the last decades at stationary ground-based sites and onboard research vessels have allowed for the accumulation of a vast quantity of experimental data on aerosol characteristics in the near-ground air layer in different regions of the Earth (Delene and Ogren, 2002; Kozlov et al., 2007; Sakerin et al., 2007). Columnar data on optical and microphysical aerosol parameters can be obtained from ground-based spectral measurements of direct and scattered solar radiation at the photometric networks AERONET (http://aeronet.gsfc.nasa.gov), SKYNET (http: //atmos.cr.chiba-u.ac.jp), ESR (http://www.euroskyrad.net), etc.

The vertical profiles of the aerosol characteristics in the atmosphere have been less studied than the horizontal variations. At present, the main source of data on aerosol properties at different altitudes is airborne observations. Data for regions over oceans were obtained during the experiments ACE-2 (Collins et al., 2000a; Öström and Noone, 2000), 
INDOEX (de Reuss et al., 2001) and ACE-Asia (Anderson et al., 2003; Redemann et al., 2003). More elaborate airborne datasets over coastal and continental locations have been acquired in the US mid-Atlantic coastal region (Hegg et al., 1997; Hartley et al., 2000), the Arctic (Brock et al., 2011; McNaughton et al., 2011), North America (Collins et al., 2000b; Han et al., 2003; Magi et al., 2005; Shinozuka et al., 2007; Schwarz et al., 2006), Africa (Johnson et al., 2008; Magi et al., 2003) and Europe (Varotsos, 2005). Comparative analyses of the microphysical and optical parameters of some principal aerosol species (Saharan dust, biomass burning aerosol, European continental pollution, eastern seaboard USA pollution and clean maritime aerosol), obtained during international field campaigns, are presented in Osborne and Haywood (2005) and Clark and Kapustin (2010).

It should be noted that data on the seasonal variability of the vertical profiles of aerosol scattering and absorption properties in the troposphere are very sparse. Among the studies that collected such data (Andrews et al., 2011) is notable: approximately 600 measurements of vertical profiles obtained over rural Oklahoma for different seasons in 2000-2007 were analysed.

The present-day, real-atmosphere aerosol studies apply a wide range of methods and facilities for the study of aerosol properties. There are two main approaches for estimating aerosol optical characteristics. One method is based on data describing the microphysical and chemical composition of the species and involves a subsequent calculation of the required optical characteristics, whereas the other relies on optical measurement data.

One advantage of the "microphysical" approach is that the model data for nearly all required optical aerosol parameters can be obtained in the spectral range of interest. The most serious disadvantage of this approach is that any restriction or distortion of the data on microphysical parameters or particle shapes leads to unpredictable errors in retrieving the optical characteristics; therefore, all parameters estimated with this approach should be carefully validated against optical measurement data.

The approach to describing the properties of atmospheric aerosol in terms of its optical characteristics in the real atmosphere is free from most of the shortcomings inherent in the microphysical simulations. The "optical" approach is considered to be disadvantageous in that the data obtained can generally be used only for observed optical characteristics and are limited to the spectral range for which the initial observation data were obtained. The applicability of the data outside these bounds requires additional investigation and validation.

In the majority of the papers cited above, vertical profiles of the aerosol radiative parameters (extinction coefficient, single scattering albedo and asymmetry factor) were calculated from the measured absorption, scattering and backscattering coefficients (following the "optical" approach). In some experiments, measurements of the optical characteristics were accompanied by determinations of the particle size distribution and chemical composition (Brock et al., 2011; Osborn and Haywood, 2005; Han et al., 2003; Johnson et al., 2008; Collins et al., 2000a,b; Magi et al., 2005). These data were used for "optical closure" aimed at comparing the Mie scattering and extinction coefficients with the respective measured values.

In this paper, we describe our approach to estimating the upward and downward solar radiative fluxes on the basis of an empirical model of the vertical profiles of tropospheric aerosol optical properties over West Siberia. We note two particular aspects that form the basis of the model.

The first aspect consists of the necessity to parameterize the relationship between aerosol characteristics and relative air humidity, the latter of which strongly affects the transformation of the microphysical parameters of the aerosol particles. The approach that we have developed is based on the principle of separate investigations of variations in the aerosol particle dry matter and aerosol condensation activity under external factors (Panchenko et al., 2004).

The second aspect of our approach lies in an empirical model constructed by combining the microphysical and optical approaches. The presented model of the vertical profiles of all of the required radiative parameters is based on the airborne sensing data of optical and microphysical characteristics of the tropospheric aerosol over West Siberia at altitudes of 0-5 km (Panchenko et al., 1998; Panchenko and Terpugova, 2002) with the season, air mass type and time of day as the input parameters. The aerosol absorption properties are taken into account through simultaneous airborne measurements of the vertical profiles of the scattering coefficient of aerosol dry matter and the mass concentration of black carbon in different seasons (Panchenko et al., 2000; Kozlov et al., 2009). These data allow us to obtain the vertical profiles of the complex refractive index of dry carbonaceous aerosol.

In the last stage, the aerosol spectral optical parameters are used for a numerical simulation of the broadband solar radiative fluxes.

\section{Empirical model of the vertical profiles of optical and microphysical aerosol characteristics}

In this section, we describe an approach applied to create a model of vertical profiles of aerosol optical and microphysical characteristics. The aerosol radiative parameters that are characteristic of typical summer conditions in West Siberia are also presented.

\subsection{Instrumentation and measurements}

The measurement instrumentation and calibration techniques used here were described in detail in earlier publications (Panchenko et al., 1996, 2000). Here, we give only a brief instrument characterisation. 
A polarized nephelometer was used for measuring the aerosol angular scattering coefficient at an angle of $45^{\circ}$ and a wavelength of $0.51 \mu \mathrm{m}$. The sensitivity of the instrument was about $1 \mathrm{Mm}^{-1}$. The nephelometer was calibrated in absolute units for each flight, using the values of the molecular scattering coefficient of pure air at the heights of $0.5,1.0,2.0$, $3.0,4.0$ and $5.0 \mathrm{~km}$ (at different pressures).

The particle size distribution function was recorded by a photoelectric particle counter in 12 channels in the radius range of $0.2-5 \mu \mathrm{m}$.

The mass concentration of the absorbing substance was measured by an aethalometer, which employed the method of measuring the diffuse absorption by a layer of particles during their deposition from airflow on a filter. The instrument is capable of measuring the mass concentration of black carbon starting from values of $0.01 \mathrm{\mu g} \mathrm{m}^{-3}$ while passing 10 201 of air through it. The aethalometer was calibrated in absolute units under laboratory conditions using a special pyrolysis generator of black carbon particles and by comparing the synchronous optical and gravimetric measurements of the black carbon content.

A number of difficulties can arise as a result of possible distortions of the studied air characteristics at sampling and transportation to the scattering volume.

The samples to be analysed were collected continuously by a direct airflow. Here, the principle difficulty is to maintain the isokinetic condition. To do this, it is necessary to satisfy a number of requirements on the geometry of the collecting device.

Possible changes in the particle number density when moving along the collection path may arise, firstly, due to their diffusion and sedimentation on the walls and, secondly, due to inertial settling on bends in the path that cannot be completely avoided in the construction of an air transport path. The inlet diameter of the photoelectric counter was $2 \mathrm{~cm}$, and it was installed at a short distance (approximately $0.5 \mathrm{~m}$ ) from the collecting device. The nephelometer and aethalometer had an inlet diameter of $1 \mathrm{~cm}$ and were arranged approximately at $3 \mathrm{~m}$ from the collecting device. Estimates made according to Fuchs (1964) and Green and Lane (1964) for the specific conditions of the experiment (air flow rates, inlet diameters, etc.) show that the photoelectric counter is capable of measuring the concentration of coarse particles without distortions (up to radius $R \sim 5 \mu \mathrm{m}$ ). The loss of submicron aerosol particles in the nephelometer and aethalometer did not exceed $1 \%$, but it can reach $10 \%$ or more for particles of $R \geq 5 \mu \mathrm{m}$. All measurements were carried out at a relative air humidity of less than $30 \%$. This was caused by the unavoidable heating of the air path, instruments and optical cells located inside the aircraft. However, hygrograms (the dependences of the angular scattering coefficient on relative humidity RH up to $\sim 90-95 \%$ ) were recorded during each flight at fixed altitudes in steps of $0.5 \mathrm{~km}$.

The meteorological parameters (temperature and relative humidity) of the air outside the aircraft and immediately in the scattering volume were recorded simultaneously with the nephelometric measurements. The true values of the scattering coefficient in situ were reconstructed on this basis.

When developing the empirical model, we used data obtained from two measurement campaigns. A model of the vertical profiles of the scattering coefficient and particle size distribution function at heights of up to $5 \mathrm{~km}$ (Panchenko et al., 1998; Panchenko and Terpugova, 2002) was constructed on the basis of airborne measurements performed from 1986-1988. The data array consists of more than 600 vertical profiles (the summer subarray includes more than 150 profiles). The input parameters of the model are geophysical factors: season, type of air mass, time of day; and measured parameters: near-ground value of the angular scattering coefficient, aerosol optical depth, vertical profiles of the temperature and relative humidity of the air.

During this measurement period, the airborne instrumentation had no devices for absorber ("soot" or black carbon (BC)) measurements. Regular monthly measurements of the aerosol scattering coefficients of dry particle matter and black carbon mass concentration, $M_{\mathrm{BC}}$, were initiated in 1999 aboard an AN-30 Optic-E airborne laboratory (Panchenko et al., 2000; Kozlov et al., 2009). The black carbon measurements were performed along 9 horizontal flight legs at altitudes of up to $7 \mathrm{~km}$. The summer data array contains 27 vertical profiles of $\mathrm{BC}$ mass concentration.

Before including the $\mathrm{BC}$ concentration data in the previously developed scheme for retrieving the optical characteristics of non-absorbing aerosol, we compared the mean seasonal profiles of the aerosol angular scattering coefficient for two measurement campaigns (Fig. 1a): 1986-1988 $\left(\mu_{\text {dry }}^{(1)}\left(45^{\circ}\right)\right)$ and 1999-2007 $\left(\mu_{\text {dry }}^{(2)}\left(45^{\circ}\right)\right)$. The average vertical profile of the mass concentration of black carbon in summer obtained in the second measurement campaign is shown in Fig. 1b.

The necessity of such a comparison arises for the following reasons. The empirical model of the vertical profiles of the aerosol scattering coefficient is based on regular airborne sensing data for the West Siberian region obtained over $2.5 \mathrm{yr}$ (1986-1988) under different synoptic and meteorological conditions. For each season, the data were classified with respect to the air mass type, pressure field and weather conditions. We compared the frequency of occurrence of different air masses and pressure field types in the data array of the first campaign with the long-term synoptic data. In addition, the measured meteorological parameters were compared with aerological sensing data for stations situated in the West Siberian region (Aleksandrovskoe, Barabinsk, Novosibirsk, and Omsk) (Koshinskii et al., 1982).

The good agreement between the analysed synoptic and meteorological characteristics of the atmosphere for the observation period and the climatic data for the region allows us to expect that the bulk of data obtained on the optical aerosol 

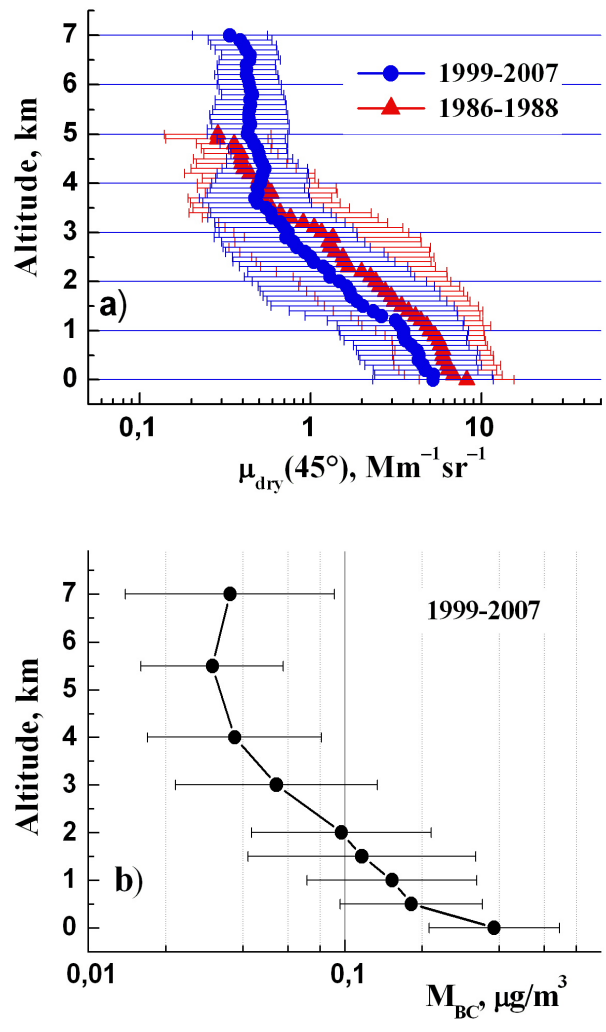

Fig. 1. The average summer vertical profiles and standard deviation of the aerosol angular scattering coefficient according to airborne measurements for 1986-1988 and 1999-2007 over West Siberia (a) and the mass concentration of black carbon for the second campaign (b).

parameters and the factors of its variability will reflect the most general regional features of West Siberia.

Fewer measurements were obtained in the second campaign (1999-2007): flights were performed once a month only, in the afternoon.

According to the data shown in Fig. 1a, the vertical profile shapes of the aerosol angular scattering coefficients $\mu_{\text {dry }}^{(1)}\left(45^{\circ}\right)$ and $\mu_{\text {dry }}^{(2)}\left(45^{\circ}\right)$ obtained for the measurement periods of 1986-1988 and 1999-2007 agree well with each other. The possibility of combining the airborne data obtained for different periods is additionally supported by the fact that the currently available series of continuing measurements of the mass concentrations of aerosol and black carbon in the nearground layer of the atmosphere, with a duration of more than $10 \mathrm{yr}$, shows no significant trend in these parameters (Kozlov et al., 2007).

Thus, the results of this analysis indicate the possibility of including data from these two different periods in an empirical model that adequately reflects the specific aerosol parameters for current summer conditions over Western Siberia.

\subsection{Scheme of the generalised model}

The proposed procedure for calculating the optical and microphysical aerosol parameters is described in this section.

A block diagram of the generalised model is shown in Fig. 2.

The first block (Sect. 2.2.1) includes a previously developed model of the vertical profiles of the scattering coefficient and the size distribution function of dry aerosol (Panchenko et al., 1998; Panchenko and Terpugova, 2002). At this stage, we use the seasonal average (summer) profiles of the angular scattering coefficient $\mu_{\text {dry }}^{(1)}\left(45^{\circ}\right)$, the relative humidity of air RH and the parameter of condensation activity $\gamma$. Parameters of the particle size distribution function were selected so that the angular scattering coefficient of the aerosol fraction calculated by the Mie theory would match the experimental seasonal average value at this altitude.

The second block (Sect. 2.2.2) of the model includes the aerosol absorption properties into the calculations: namely, the seasonal average values of the mass concentration of black carbon $M_{\mathrm{BC}}(z)$ at different heights (Kozlov et al., 2009). Then, the optical constants (real and imaginary parts of the refractive index) of the dry aerosol fractions are calculated by the simple mixture rule.

In the next stage of calculations, the seasonal average vertical profile of the relative humidity $\mathrm{RH}(z)$ and the parameter of condensation activity $\gamma(z)$, which determines the dependence of the aerosol parameters on RH (Hanel, 1976), are included in the calculations (Sect. 2.2.3). The parameters of wet aerosol are calculated here (i.e., recalculated for the actual relative humidity): the median radii and volume concentrations of submicron and coarse aerosol fractions and the real and imaginary parts of the refractive index.

Finally, by applying the Mie theory, the radiative parameters (spectral extinction coefficient, single scattering albedo, scattering phase function) are calculated at all prescribed altitudes $z$ (Sect. 2.2.4) and are used to simulate the upward $\left(F^{\uparrow}\right)$ and downward $\left(F^{\downarrow}\right)$ radiation fluxes at different atmospheric levels $z$ (Sect. 3).

\subsubsection{Vertical profiles of the aerosol size distributions}

The measured aerosol size distribution functions at altitudes of $0,0.5,1.0,1.5,2.0,3.0,4.0$ and $5.0 \mathrm{~km}$ were fitted by a sum of two lognormal functions (Panchenko et al., 1998). Then, the angular scattering coefficient of the dry fraction $\mu_{\text {dry }}\left(45^{\circ}\right)$ was calculated with Mie formulas using the parameters of submicron $(s)$ and coarse $(c)$ fractions (median radius $R_{i}$, standard deviation of the radius logarithm $v_{i}$ and volume concentration $V_{i}, i=\mathrm{s}, \mathrm{c}$ ) at each altitude.

Aerosol particles were assumed to be non-absorbing, with the real part of the refractive index being $n_{\mathrm{aer}}=1.5$. Then, the volume concentrations $V_{i}, i=\mathrm{s}, \mathrm{c}$, were recalculated so that the obtained value $\mu_{\mathrm{dry}}\left(45^{\circ}\right)$ would coincide with the average seasonal value $\mu_{\mathrm{dry}}^{(1)}\left(45^{\circ}\right)$ and so that the ratio 


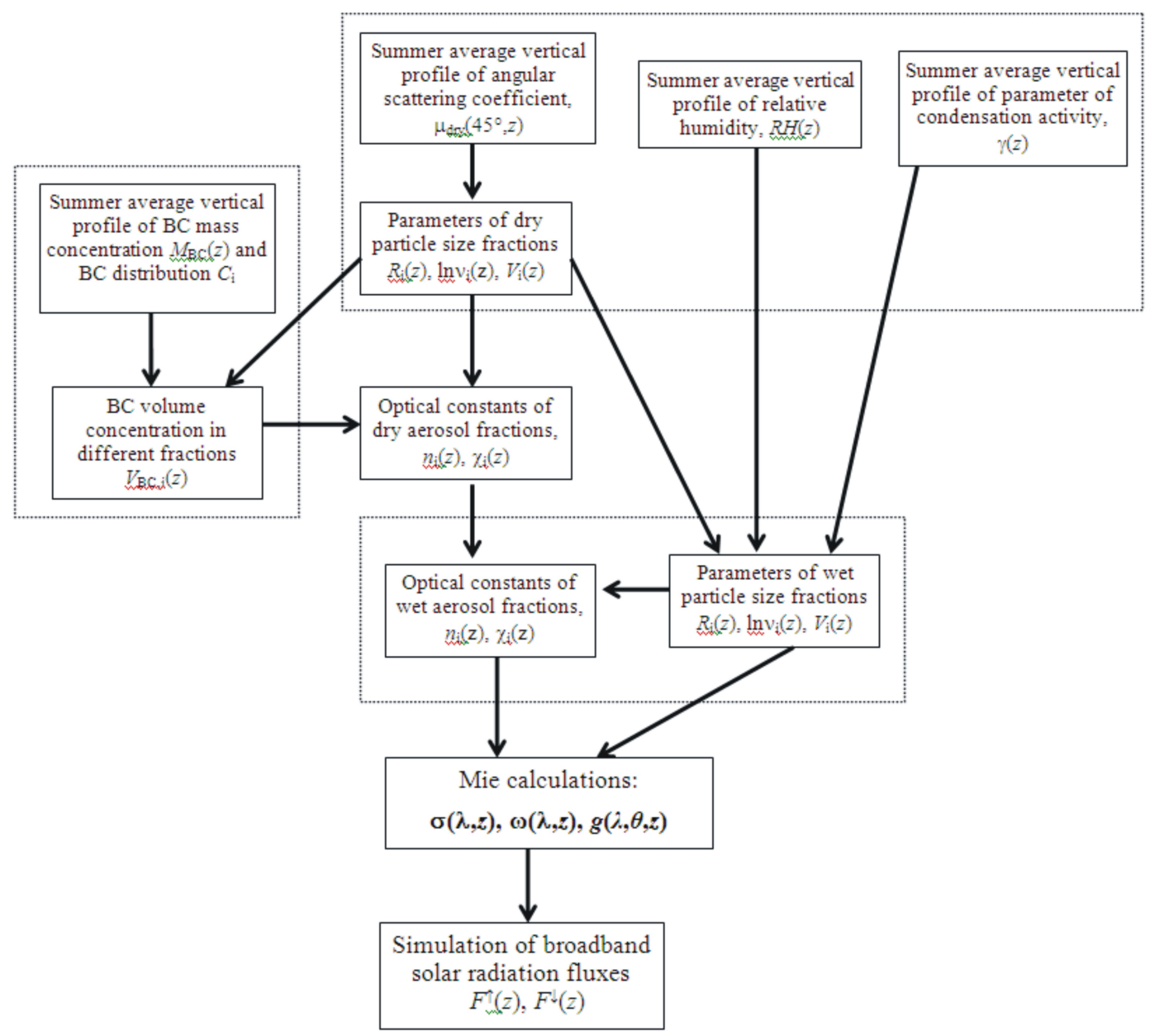

Fig. 2. Block diagram of the model.

between $V_{\mathrm{s}}$ and $V_{\mathrm{c}}$ would remain constant (Panchenko et al., 1996).

Table 1 presents the average scattering coefficients of the aerosol dry matter and relative humidity measured at these altitudes (Panchenko et al., 1996), as well as the distribution parameters $R_{i}, v_{i}$ and $V_{i}$ adjusted for both particle fractions, $i=\mathrm{s}, \mathrm{c}$.

In Sects. 2.2.2-2.2.3, all of the characteristics (volume and mass concentrations of black carbon, refractive index) are calculated at all altitudes.

\subsubsection{Estimation of the complex refractive index of dry aerosol}

In the following simulations, we assume $\mathrm{BC}$ to be the only absorbing substance.

The estimation of the refractive index depends on the form in which black carbon is present in the atmosphere. Previous estimates of the single scattering albedo $(\omega)$ made under different assumptions about the content of black carbon showed that the absolute value of the single scattering albedo and its spectral dependence vary substantially, depending on whether black carbon exists as a separate fraction (external mixture) or is uniformly distributed in aerosol particles (internal mixture) (Terpugova et al., 2005). Moreover, irrespective of which (internal or external) mixture is hypothesized, the relative content of black carbon may also depend on the particle size.

Data from particular experiments dealing with black carbon particle size distributions are available in the literature (Hitzenberger and Tohno, 2001; Kozlov et al., 2002; Höler et al., 2002; Delene and Ogren, 2002). Their results indicate that particles with radii of $0.1-0.12 \mu \mathrm{m}$ contain the largest amount of black carbon and that its relative content decreases with the particle size. An analysis of BC impactor measurements made in 1998-1999 in Vienna and Uji (Japan) (Höler et al., 2002) shows that large particles contain approximately $10 \%$ of the total $\mathrm{BC}$ mass, with the remaining $90 \%$ distributed in approximately equal parts as microdispersed (less than 0.1$)$ and submicron particles $(0.1-1 \mu \mathrm{m})$. Delene and Ogren (2002) reported that the average contribution of coarse particles to the total absorption coefficient varies from 7 to 
Table 1. The mass concentrations of the absorbing substance $M_{\mathrm{BC}}^{*}$, angular scattering coefficients for the dry matter $\mu_{\mathrm{dry}}\left(45^{\circ}\right)$, relative humidity RH and parameters of the lognormal distributions (median radius $R$, standard deviation of the radius logarithm $v$ and volume concentration of the fraction $V$ ) for the submicron and coarsely dispersed fractions at different altitudes $z$. (The values of $M_{\mathrm{BC}}^{*}$ were calculated based on Eq. 1 in Sect. 2.2.2.)

\begin{tabular}{|c|c|c|c|c|c|c|c|c|c|}
\hline \multirow{2}{*}{$\begin{array}{l}z, \\
\mathrm{~km}\end{array}$} & \multirow{2}{*}{$\begin{array}{l}M_{\mathrm{BC}}^{*}, \\
\mu \mathrm{g} \mathrm{m}^{-3}\end{array}$} & \multirow{2}{*}{$\begin{array}{l}\mu_{\mathrm{dry}}\left(45^{\circ}\right) \\
\mathrm{Mm}^{-1} \mathrm{sr}^{-1}\end{array}$} & \multirow{2}{*}{$\begin{array}{c}\mathrm{RH}, \\
\%\end{array}$} & \multicolumn{3}{|c|}{ Submicron fraction $(i=\mathrm{s})$} & \multicolumn{3}{|c|}{ Coarsely dispersed fraction $(i=\mathrm{c})$} \\
\hline & & & & $\ln v_{\mathrm{s}}$ & $R_{\mathrm{S}}, \mu \mathrm{m}$ & $V_{\mathrm{s}}$ & $\ln v_{\mathrm{c}}$ & $R_{\mathrm{c}}, \mu \mathrm{m}$ & $V_{\mathrm{c}}$ \\
\hline 0 & 1.16 & 9.77 & 72 & 0.8 & 0.114 & $1.548 \mathrm{E}-11$ & 0.65 & 2.078 & $1.145 \mathrm{E}-11$ \\
\hline 0.5 & 0.634 & 7.07 & 70 & 0.8 & 0.096 & $1.414 \mathrm{E}-11$ & 0.65 & 1.804 & $1.573 \mathrm{E}-11$ \\
\hline 1 & 0.556 & 6.18 & 75 & 0.8 & 0.098 & $1.236 \mathrm{E}-11$ & 0.65 & 1.797 & $1.321 \mathrm{E}-11$ \\
\hline 1.5 & 0.458 & 5.09 & 74 & 0.8 & 0.098 & $1.018 \mathrm{E}-11$ & 0.65 & 1.791 & $1.044 \mathrm{E}-11$ \\
\hline 2 & 0.417 & 3.48 & 71 & 0.8 & 0.096 & $6.956 \mathrm{E}-12$ & 0.65 & 1.784 & $6.841 \mathrm{E}-12$ \\
\hline 3 & 0.248 & 2.08 & 69 & 0.8 & 0.095 & $4.156 \mathrm{E}-12$ & 0.65 & 1.771 & $3.738 \mathrm{E}-12$ \\
\hline 4 & 0.091 & 0.61 & 62 & 0.8 & 0.092 & $1.213 \mathrm{E}-12$ & 0.65 & 1.758 & $9.914 \mathrm{E}-13$ \\
\hline 5 & 0.045 & 0.30 & 53 & 0.8 & 0.089 & $6.022 \mathrm{E}-13$ & 0.65 & 1.745 & $4.435 \mathrm{E}-13$ \\
\hline
\end{tabular}

$20 \%$ depending on the anthropogenic loading in the region of observation.

Based on the above cited works, we performed calculations using the hypothesis that $90 \%$ of the black carbon is localized in the submicron fraction and that $10 \%$ belongs to the coarse fraction.

Here, it should be noted that measurements of the black carbon mass concentration were carried out in the second campaign (1999-2007), whereas the model of the vertical profiles of the scattering coefficient was created from the data from the first campaign (1986-1988). Thus, to match the data used for estimating the volume concentration of black carbon in the model calculations, the coefficient was introduced as equal to the ratio of the average aerosol angular scattering coefficients in the first and second campaigns:

$M_{\mathrm{BC}}^{*}=M_{\mathrm{BC}} \mu_{\mathrm{dry}}^{(1)}\left(45^{\circ}\right) / \mu_{\mathrm{dry}}^{(2)}\left(45^{\circ}\right), \quad V_{\mathrm{BC}}=M_{\mathrm{BC}}^{*} / \rho_{\mathrm{BC}}$

where $M_{\mathrm{BC}}^{*}$ is the mass concentration of black carbon used for calculations of the complex refractive index (Table 1), $\rho_{\mathrm{BC}}$ is the density of black carbon matter, $\rho_{\mathrm{BC}}=1.85 \mathrm{~g} \mathrm{~cm}^{-3}$ (Gelencser, 2004; Bond and Bergstrom, 2006).

The volume concentration of black carbon in every $i$-th fraction, $i=\mathrm{s}$, c, was calculated using the formula

$V_{\mathrm{BC}, i}=C_{i} V_{\mathrm{BC}}$,

where $C_{i}$ is the portion of black carbon in the $i$-th aerosol fraction $\left(C_{\mathrm{s}}=0.9, C_{\mathrm{c}}=0.1\right.$, in accordance with the accepted hypothesis).

The refractive index of the mixture in each fraction $\left(n_{\mathrm{dry}, i}\right.$; $\left.\chi_{\mathrm{dry}, i}\right), i=\mathrm{s}$, c, was determined according to the internal mixture rule (as a sum of the refractive indices of black carbon and non-absorbing aerosol, taken with the weights corresponding to their fractions at each altitude):

$$
\begin{aligned}
& n_{\mathrm{dry}, i}=\left(n_{\mathrm{aer}} \times V_{\mathrm{aer}, i}+n_{\mathrm{BC}} \times V_{\mathrm{BC}, i}\right) /\left(V_{\mathrm{aer}, i}+V_{\mathrm{BC}, i}\right), \\
& \chi_{\mathrm{dry}, i}=\chi_{\mathrm{BC}} \times V_{\mathrm{BC}, i} /\left(V_{\mathrm{aer}, i}+V_{\mathrm{BC}, i}\right),
\end{aligned}
$$

where $V_{\text {aer, } i}$ is the volume concentration of the non-absorbing aerosol in the $i$-th fraction. The complex refractive index of black carbon was set to be $\left(n_{\mathrm{BC}}=1.8, \chi_{\mathrm{BC}}=0.74\right)$ (Gelencser, 2004; Bond and Bergstrom, 2006).

\subsubsection{Estimation of the complex refractive index of wet aerosol}

In the next stage, we recalculated the refractive index of dry aerosol in accordance with the mean seasonal relative humidities $\mathrm{RH}$ at different altitudes obtained during airborne sensing (Panchenko et al., 1996).

The dependences of the aerosol parameters (radius, volume concentration and scattering coefficient) on relative humidity were approximated by the Hanel formula (Hanel, 1976). In particular, for the angular scattering coefficient, the formula can be written as

$\mu_{\mathrm{wet}}\left(45^{\circ}\right)=\mu_{\mathrm{dry}}\left(45^{\circ}\right) \times(1-\mathrm{RH}(z))^{-\gamma(z)}$,

where $\mu_{\text {wet }}\left(45^{\circ}\right)$ is the scattering coefficient under the ambient conditions, $\mu_{\mathrm{dry}}\left(45^{\circ}\right)$ is the dry scattering coefficient at relative humidity $<30 \%$, and $\operatorname{RH}(z)$ and $\gamma(z)$ are the mean seasonal relative humidity and parameter of the condensation activity at a height of $z$.

The $\gamma$ values at different altitudes, except for those at ground level $z=0$, are among the input parameters of the empirical model; they were obtained in the first measurement campaign (1986-1988) (Panchenko et al., 1996). The mean seasonal data from multi-year measurements in Tomsk were taken as the near-ground $\gamma$ value (Panchenko et al., 2005). For summer, the condensation activity parameter was $\gamma=0.3$ at $z=0$, with $\gamma=0.5$ at all other altitudes. The results of processing more than 200 realisations of hygrograms at heights of up to $5 \mathrm{~km}$ showed that the differences between the $\gamma$ values at $z=0$ and other heights are more than $95 \%$ statistically significant, according to the "Student's t-test" (Panchenko et al., 1996). The angular scattering coefficient $\mu_{\text {dry }}\left(45^{\circ}\right)$ was 

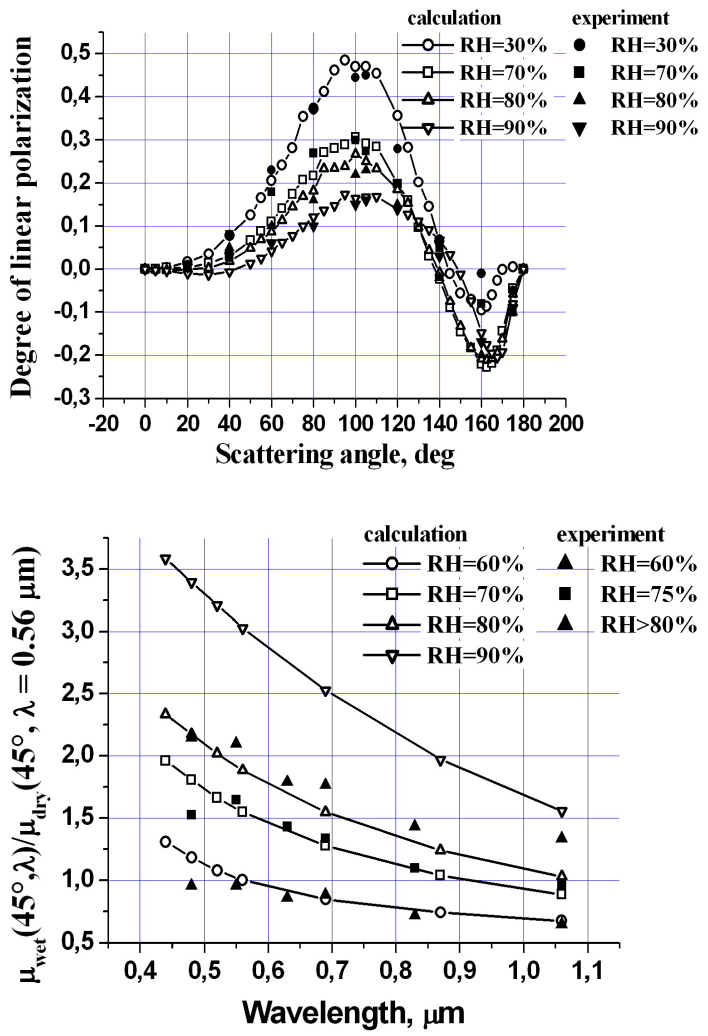

Fig. 3. Comparison of calculated and measured ground-level aerosol parameters: the degree of linear polarisation of the scattered radiation (a) and spectral dependence of the ratio of the scattering coefficient for several relative humidity values on the scattering coefficient of the aerosol dry matter (b).

the main characteristic measured in the airborne experiments. For the submicron aerosol fraction, this characteristic is linearly related to the particle volume concentration; therefore, for the wet aerosol, the following formula is valid:

$V_{\text {wet,s }}=V_{\text {dry,s }} \times(1-\mathrm{RH}(z))^{-\gamma(z)}$,

where $V_{\text {dry,s }}$ and $V_{\text {wet,s }}$ are the volume concentrations of the respective "dry" and "wet" (ambient) aerosol.

To decide whether to include the effect of humidity on coarse particles, we compared data from earlier experiments with the aerosol optical parameters calculated on condition that only the submicron fraction is hygroscopic. Figure 3 presents the calculated values of the degree of linear polarization of the scattered radiation (a) and the spectral dependence of the ratio of the scattering coefficient at several relative humidity values to the scattering coefficient of the aerosol dry matter (b) in comparison with experimental data (Kabanov et al., 1988).

As the comparison showed a good agreement between the model and experimental characteristics, in further calculations, we considered only variations in wetting of the submicron fraction.
Table 2. Real and imaginary parts of the aerosol complex refractive indices of the submicron and coarse fractions.

\begin{tabular}{lcccc}
\hline$z, \mathrm{~km}$ & $n_{\mathrm{S}}$ & $n_{\mathrm{c}}$ & $\chi_{\mathrm{s}}$ & $\chi_{\mathrm{c}}$ \\
\hline 0 & 1.4486 & 1.50 & 0.0171 & 0.0040 \\
0.5 & 1.4266 & 1.50 & 0.0087 & 0.0016 \\
1 & 1.4182 & 1.50 & 0.0079 & 0.0017 \\
1.5 & 1.4200 & 1.50 & 0.0081 & 0.0018 \\
2 & 1.4261 & 1.50 & 0.0113 & 0.0024 \\
3 & 1.4294 & 1.50 & 0.0117 & 0.0027 \\
4 & 1.4413 & 1.50 & 0.0161 & 0.0037 \\
5 & 1.4538 & 1.50 & 0.0179 & 0.0041 \\
\hline
\end{tabular}

The refractive index $\left(n_{\text {wet,s }} \chi_{\text {wet,s }}\right)$ of the submicron aerosol fraction was estimated under the assumption that, during wetting, the volume of particles increases due to water uptake only:

$n_{\text {wet, } \mathrm{s}}=\left(n_{\text {dry,s }} V_{\mathrm{s}}+n_{\mathrm{w}} V_{\mathrm{w}}\right) / V_{\mathrm{wet}, \mathrm{s}}$,

$\chi_{\text {wet,s }}=\chi_{\text {dry,s }} V_{\mathrm{s}} / V_{\text {wet,s }}$.

Here, $n_{\mathrm{w}}=1.33$ is the refractive index of the liquid water and $V_{\mathrm{w}}=V_{\text {wet,s }}-V_{\text {dry,s }}$ is the condensed water volume, i.e., the increment in the volume of the aerosol particles.

The values of the complex refractive index of the submicron and coarse fractions used for further calculations are presented in Table 2.

\subsubsection{Calculation of aerosol parameters}

In the next stage, Mie calculations of the extinction coefficient $\sigma(\lambda, z)$, single scattering albedo $\omega(\lambda, z)$ and scattering phase functions $g(\lambda, \theta, z)(\theta$ is the scattering angle) were performed at the prescribed atmospheric levels in the altitude range of $0-5 \mathrm{~km}$. The optical depth $\tau_{\mathrm{a}}(\lambda)$ was calculated as the integral of the aerosol extinction coefficient in the altitude range of $0-5 \mathrm{~km}$.

The normalised spectral behaviour of $\tau_{\mathrm{a}}(\lambda) / \tau_{\mathrm{a}}(\lambda=$ $0.55 \mu \mathrm{m})$ in the wavelength range of $0.37-1.02 \mu \mathrm{m}$ and the Ångström exponent $\alpha(0.44-0.87 \mu \mathrm{m})$ are in good agreement with multi-year sunphotometer measurements collected for the territory of Siberia (Sakerin and Kabanov, 2007) (Fig. 4a). The $\alpha(0.44-0.87 \mu \mathrm{m})$ value is also close to the Angström exponent for the OPAC model of continental aerosol (continental average, $\mathrm{RH}=70 \%$; Hess et al., 1998) and is equal to approximately 1.4.

The aerosol single scattering albedo $\omega(\lambda, z)$ varies quite substantially with altitude: at all wavelengths, the maximum values $\omega(\lambda, z) \sim 0.92-0.93$ are observed in the mixing layer at $0.5-1.5 \mathrm{~km}$; outside this layer, they decrease towards the Earth's surface and with increasing altitude (Fig. 4b). At the same time, the altitude variations in the asymmetry parameter $\langle g(\lambda, z)>$ of the scattering phase function are much smaller, not exceeding $\sim 0.02$ throughout the entire wavelength range of $0.44-0.87 \mu \mathrm{m}$ (Fig. $4 \mathrm{c}$ ). 


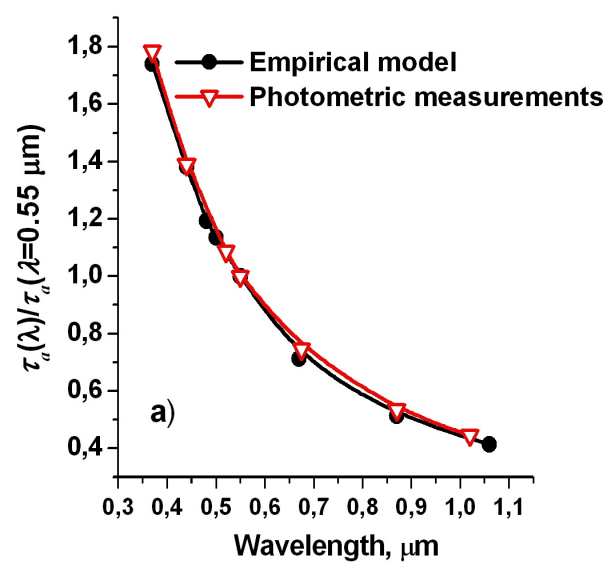

A detailed comparison between the presented average summer profiles of the single scattering albedo and asymmetry factor and the airborne measurements obtained by other authors is rather problematic.

The first reason is that these results correspond to different geographic and climatic environments. Difficulty also arises from the fact that the available data from regular measurements of the vertical profiles of $\omega(\lambda, z)$ mainly refer to dry aerosol (Han et al., 2003; Andrews et al., 2011; McNaughton et al., 2011; Brock et al., 2011; Taubman et al., 2006; Magi et al., 2003). Only a few authors (e.g., Öström and Noone, 2000; Magi et al., 2003, 2005; Shinozuka et al., 2007) have attempted to simulate $\omega(\lambda, z)$ variations while considering changing aerosol parameters under the effect of the real relative humidity of air.

We use the obtained values $\omega(\lambda, z)$ and $\langle g(\lambda, z)\rangle$

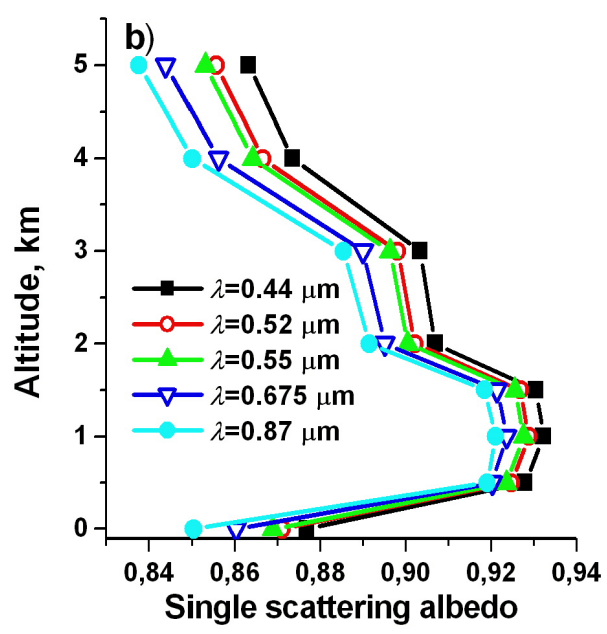

for comparison with the columnar single scattering albedo $\omega^{\mathrm{atm}}(\lambda)$ and the asymmetry factor of the scattering phase function $<g^{\operatorname{atm}}(\lambda)>$. One of the few sources for data on the columnar aerosol optical characteristics is the Dubovik-King algorithm (Dubovik and King, 2000) for the AERONET site located in the city of Tomsk (http://aeronet.gsfc.nasa.gov). However, the data array collected since 2002 (in particular, the complex refractive index and the single scattering albedo) at Level 2.0 characterises the aerosol state only under conditions of high atmospheric turbidity $\tau_{\mathrm{a}}(0.44 \mu \mathrm{m}) \geq 0.4$, caused mainly by forest fires. A method for the retrieval of $\omega^{\mathrm{atm}}(\lambda)$ and $<g^{\mathrm{atm}}(\lambda)>$ based on measurements of spectral aerosol optical depth (AOD) and cloudless sky brightness in solar almucantar was proposed by the authors Bedareva and Zhuravleva $(2011,2012)$. It provides for an estimation of these parameters in the visible wavelength range under conditions of weak to moderate atmospheric turbidity $\tau_{\mathrm{a}}(0.44 \mu \mathrm{m}) \leq 0.4$.

The columnar aerosol optical characteristics are presented in Table 3. The average values $\left\langle\omega^{\mathrm{atm}}(\lambda)\right\rangle$ and $\left\langle<g^{\mathrm{atm}}(\lambda)>\right\rangle$ retrieved from the data obtained at the Tomsk AERONET station in summer (June-August) for 2004-2009 using algorithms (Dubovik and King, 2000) under the conditions of $\tau_{\mathrm{a}}$ $(0.44 \mu \mathrm{m}) \geq 0.4$ and (Bedareva and Zhuravleva, 2011, 2012) at $\tau_{\mathrm{a}}(0.44 \mu \mathrm{m}) \leq 0.4$ are also given here. Furthermore, Table 3 presents data on the optical characteristics of continental average aerosol $(\mathrm{RH}=70 \%)$ from the OPAC model (Hess et al., 1998).

A comparison of the data shows satisfactory agreement between the $\left\langle\omega^{\mathrm{atm}}(\lambda)\right\rangle$ and $\left\langle<g^{\mathrm{atm}}(\lambda)>\right\rangle$ values obtained from airborne sensing and the method presented in Bedareva and Zhuravleva $(2011,2012)$. The single scattering albedo obtained from ground-based photometric measurements (Dubovik and King, 2000) under conditions of high turbidity is slightly greater than that obtained with the model presented here. In our opinion, this is not only due to the difference in retrieval methods of aerosol radiative parameters, but to the fact that data under conditions of $\tau_{\mathrm{a}}(0.44 \mu \mathrm{m}) \geq 0.4$ correspond to situations influenced by Siberian forest fires.

Fig. 4. Spectral behaviour of the normalised aerosol optical depth according to multi-year airborne and ground-based photometric measurements (a) and vertical profiles of the single scattering albedo (b) and asymmetry factor (c) for the altitude range of $0-5 \mathrm{~km}$ in the summer. 
Table 3. The columnar single scattering albedo and the asymmetry factor obtained from the empirical model in comparison with the methods of Dubovik and King (2000) and Bedareva and Zhuravleva $(2011,2012)$ and the continental aerosol model $(\mathrm{RH}=70 \%)$ presented in the model OPAC (Hess et al., 1998).

\begin{tabular}{lccccl}
\hline & $\lambda, \mu \mathrm{m}$ & $\begin{array}{c}\text { Our } \\
\text { model }\end{array}$ & $\begin{array}{c}\text { Dubovik } \\
\text { and } \\
\text { King } \\
(2000)\end{array}$ & $\begin{array}{c}\text { Bedareva } \\
\text { and } \\
\text { Zhuravleva } \\
(2011, \\
2012)\end{array}$ & $\begin{array}{l}\text { Hess } \\
\text { et al. } \\
(1998)\end{array}$ \\
\hline$\left\langle\omega^{\text {atm }}(\lambda)\right\rangle$ & 0.440 & 0.92 & 0.94 & 0.92 & 0.92 \\
& 0.675 & 0.90 & 0.93 & 0.90 & 0.9 \\
& 0.870 & 0.90 & 0.92 & - & 0.87 \\
\hline$\left\langle\left\langle g^{\operatorname{atm}}(\lambda)\right\rangle\right\rangle$ & 0.440 & 0.67 & 0.69 & 0.68 & 0.72 \\
& 0.675 & 0.63 & 0.61 & 0.61 & 0.69 \\
& 0.870 & 0.62 & 0.57 & - & 0.66 \\
\hline
\end{tabular}

As shown in Kozlov et al. (2008), the intrusion of forest fire smoke in the region of observation leads to an increased single scattering albedo in comparison with background conditions. As for the model of continental aerosol OPAC, its single scattering albedo data are close to the values we obtained for the territory of West Siberia, while the qualitative differences in the asymmetry factor values are much more significant.

\section{Radiative calculations}

The broadband solar radiation fluxes in the molecularaerosol, plane-parallel atmosphere were calculated using a previously developed Monte Carlo algorithm (Zhuravleva et al., 2009). The shortwave spectral interval of $0.2-5.0 \mu \mathrm{m}$ was divided into 31 subranges (Slingo, 1989).

The Monte Carlo method was used to solve the radiative transfer equation within each of the 31 subranges (forward photon tracing method), analogously to that described, for example, in O'Hirok and Gautier (1998) and Mayer and Kylling (2005). To account for the molecular absorption within each spectral band $\Delta \lambda$, we used an approach based on the use of the transmission function of atmospheric gases $T_{\Delta \lambda}$, which is described in detail in Zhuravleva (2008). In essence, this approach consists of a simulation of the photon trajectories in the molecular-aerosol atmosphere while neglecting molecular absorption, and statistical estimates such as $\left(\sum_{i=1}^{N_{\text {tr }}} \sum_{j=1}^{m_{i}} T_{\Delta \lambda}\left(l_{i j}\right)\right) / N_{\text {tr }}$ are used for calculations of the radiation fluxes at $z=z^{*}$. Here, $N_{\text {tr }}$ is the number of trajectories, $m_{i}$ is the number of crossings at the plane $z=z^{*}$ by a photon in the $i$-th trajectory along the direction of motion, and $l_{i j}$ is the photon path length in the $i$-th trajectory from the point at the top of the atmosphere to the $j$-th crossing of the level $z=z^{*}$ by the photon. It is assumed that the aerosol optical characteristics (extinction coefficient, single scattering albedo, scattering phase function of aerosol particles), molecular scattering coefficient and albedo of the underlying surface are constant within the $i$-th spectral subrange.

The transmission function of the atmospheric gases within each band was approximated by a finite exponential series (correlated $k$-distribution method; Lacis and Oinas, 1991) as in Ricchiazzi et al. (1998), Clough et al. (2004), Mayer and Kylling (2005) and García et al. (2012). Molecular absorption coefficients were calculated, taking into account all atmospheric gases included in the AFGL meteorological model (Anderson et al., 1986) using the HITRAN2008 database and the MT_CKD v.2.4 continuum model (http:// rtweb.aer.com/continuum_frame.html). The results of the numerical simulation showed that the errors in calculating the transmission function in most of the considered shortwave ranges do not exceed $1 \%$. The exceptions are two spectral regions, $4.6-4.8$ and $4.8-5.0 \mu \mathrm{m}$, in which the errors reach $5 \%$. The use of a more sophisticated method that accounts for the overlap of the absorption bands of different gases (Firsov and Chesnokova, 1998) makes it possible to reduce this error to $\sim 1 \%$. However, because the broadband radiation fluxes are the main interest in this work and because the contribution of the aforementioned spectral regions to the total flux $(0.2-5 \mu \mathrm{m})$ is less than $0.2 \%$, we do not apply this more accurate but laborious procedure. The comparisons showed the numerical simulation results to be in satisfactory agreement with the results of line-by-line calculations and field measurements (Tvorogov et al., 2008; Chesnokova et al., 2009).

For the computations presented below, the transmission function was calculated using a regional model of the temperature, pressure and water vapour profiles (Komarov and Lomakina, 2008). The total water vapour content was assumed to be $W=1.9 \mathrm{~g} \mathrm{~cm}^{-2}$, the total ozone content was equal to $336 \mathrm{DU}$ according to TOMS satellite data (ftp:// toms.gsfc.nasa.gov), and the total $\mathrm{CO}_{2}$ content in the atmosphere was $380 \mathrm{ppm}$. (These values correspond to summer averages for the territory of West Siberia; Sakerin and Kabanov, 2007; Sakerin et al., 2009; Arshinov et al., 2009.) The data of Fontenla et al. (1999) were used for the extraterrestrial spectral solar radiance.

The incident radiation was reflected from the underlying surface according to the Lambert law. The surface albedo was specified using the MODIS satellite measurement data (Moody et al., 2005) for the region of Tomsk.

\subsection{The influence of spectral variations in aerosol radiative parameters on broadband flux calculations}

The numerous comparisons presented above between the calculation results and the near-ground measurement data showed that, within standard measurement errors, the empirical model provides for a retrieval of the scattering coefficients and the angular dependence of the scattering matrix 
elements in the wavelength range of $0.44-0.87 \mu \mathrm{m}$. This is quite consistent with the measurement capacity of the airborne instrumentation (nephelometer and photoelectric counter).

The nephelometer, operating in the visible wavelength range, adequately represents the optical properties of mainly submicron particles $(R=0.05-0.7 \mu \mathrm{m})$ (Panchenko et al., 2004). The photoelectric counter, measuring particles in the radius range of $0.3-5 \mu \mathrm{m}$, offers a means to extend the range of optical characteristic estimation towards longer wavelengths. However, the accuracy in measuring particle concentrations closer to the upper size limit (accounting for possible distortions in the airborne air intake) becomes increasingly lower compared to the case in which smaller particles are recorded.

At the same time, calculations of the upward $F^{\uparrow}(z)$ and downward $F^{\downarrow}(z)$ solar radiation fluxes require data on the spectral dependence of the extinction $\sigma(\lambda, z)$ and scattering $\sigma_{\mathrm{s}}(\lambda, z)$ coefficients, as well as on the spectral dependence of the scattering phase functions $g(\lambda, \theta, z)$ throughout the entire wavelength range of $0.2-5.0 \mu \mathrm{m}$. It is, therefore, relevant to consider how critical it is for broadband flux simulations to account for the spectral dependence of aerosol optical characteristics beyond the range of $0.44-0.87 \mu \mathrm{m}$.

To address this issue, we performed additional numerical experiments using the OPAC model of continental aerosol (continental average, $\mathrm{RH}=70 \%$, Hess et al., 1998). This model contains all input aerosol parameters necessary for the numerical simulation, by including both the wavelength dependence in the range of $0.25-5 \mu \mathrm{m}$ and the vertical profiles of the optical characteristics for altitudes of $0-35 \mathrm{~km}$.

As a basic variant, we took the calculation performed with the assumption that the aerosol extinction coefficients $\sigma(\lambda, z)$ are constant outside the wavelength interval of $0.37-1.02 \mu \mathrm{m}: \sigma(\lambda<0.37 \mu \mathrm{m}, z)=\sigma(\lambda=0.37 \mu \mathrm{m}, z)$, $\sigma(\lambda>1.02 \mu \mathrm{m}, z)=\sigma(\lambda=1.02 \mu \mathrm{m}, z)$, while $g(\lambda, \theta, z)$ and $\omega(\lambda, z)$ exactly corresponded to the model data (Fig. 5a and $b$ ). The spectral AOD dependence was modified for the following reason. Based on the multi-year ground-based observations for the territory of Siberia, it was shown that the AOD varies only slightly at $\lambda>1 \mu \mathrm{m}$; therefore, we can adopt $\tau_{\mathrm{a}}(\lambda>1 \mu \mathrm{m}) \sim \tau_{\mathrm{a}}(\lambda \sim 1 \mu \mathrm{m})$ (Sakerin and Kabanov, 2007).

The simulation results for fluxes in the range of $0.2-5 \mu \mathrm{m}$ showed that at $\tau_{\mathrm{a}}(0.5 \mu \mathrm{m})=0.262$ and for solar zenith angles $\mathrm{SZA} \sim 35-60^{\circ}$, the direct radiation fluxes $S(z=0)$, calculated without AOD spectral modification, were overestimated by $\sim 8-10 \mathrm{~W} \mathrm{~m}^{-2}$, while the diffuse radiation fluxes $F_{\mathrm{S}}^{\downarrow}(z=0)$ were underestimated by $\sim 4-6 \mathrm{~W} \mathrm{~m}^{-2}$. Importantly, the main contribution to the radiative flux discrepancies comes precisely from the region $\lambda>1 \mu \mathrm{m}$. Undoubtedly, the differences can be more dramatic with increasing AOD. However, according to long-term satellite measurements over West Siberia and near-ground measurements for
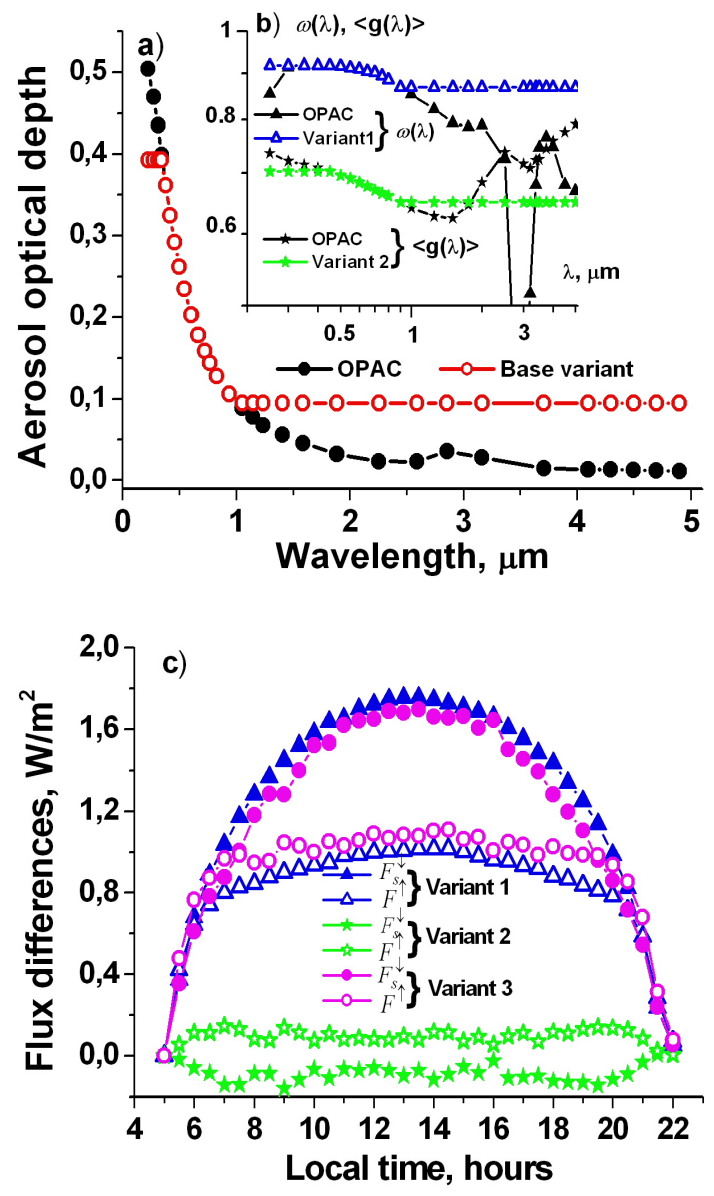

Fig. 5. Spectral behaviour of the aerosol optical depth (a) and single scattering albedo and asymmetry factor (b) in the OPAC model (continental average $\mathrm{RH}=70 \%$ ) in the basic variant and in variants 1 and 2 and the difference between the diffuse downward $F_{\mathrm{s}}^{\downarrow}$ $(z=0)$ and upward $F^{\uparrow}(z=100 \mathrm{~km})$ radiation fluxes (between the basic variant and variants $1-3)(\mathbf{c}) ; \tau_{\mathrm{a}}(0.5 \mu \mathrm{m})=0.262$.

the city of Tomsk, the respective average AOD values in summer are close to $\tau_{\mathrm{a}}(0.5 \mu \mathrm{m}) \sim 0.16$ (Sakerin and Kabanov, 2007; Sakerin et al., 2009; Zhuravleva et al., 2009). Thus, in this paper, we do not discuss the change in radiative flux differences caused by AOD variations.

The sensitivity of the radiative fluxes to the spectral dependence of the scattering phase function and single scattering albedo was estimated by considering the following cases (Fig. 5a and b):

- variant 1 (the single scattering albedo is assumed to be constant outside the interval of $0.44-0.87 \mu \mathrm{m})$ : $\omega(\lambda<0.44 \quad \mu \mathrm{m}, z)=\omega(\lambda=0.44 \quad \mu \mathrm{m}, z), \omega(\lambda>0.87$ $\mu \mathrm{m}, z)=\omega(\lambda=0.87 \mu \mathrm{m}, z)$;

- variant 2 (the scattering phase functions are assumed to be constant outside the interval of 0.44 $0.87 \mu \mathrm{m}): g(\lambda<0.44 \mu \mathrm{m}, \theta, \mathrm{z})=\mathrm{g}(\lambda=0.44 \mu \mathrm{m}, \theta, z)$, $g(\lambda>0.87 \mu \mathrm{m}, \theta, z)=g(\lambda=0.87 \mu \mathrm{m}, \theta, z)$; 
- variant 3 (the scattering phase functions and the single scattering albedo are assumed to be constant outside the interval of $0.44-0.87 \mu \mathrm{m}$ and equal to the respective boundary values) (see variants 1 and 2).

The results of the numerical experiments indicate that when the spectral variations in the scattering phase functions and single scattering albedos are neglected, the biases are no greater than $2 \mathrm{~W} \mathrm{~m}^{-2}$ and $1 \mathrm{~W} \mathrm{~m}^{-2}$ in the calculations of the instantaneous fluxes of diffuse downward $(z=0)$ and upward radiation $(z=100 \mathrm{~km})$ (Fig. 5c). This discrepancy in the radiative fluxes is small because a significant variation in $\omega(\lambda, z)$ and $g(\lambda, \theta, z)$ arises in the spectral bands of moderate to strong water vapour absorption $(\lambda>1.25 \mu \mathrm{m})$, as well as in the spectral bands whose contribution to the broadband radiative flux is small due to low values of solar radiation incident on the top of the atmosphere. Evidently, for situations in which the spectral behaviour of the aerosol optical characteristics is more pronounced, especially for $\lambda<1.25 \mu \mathrm{m}$, neglect of the spectral dependences of $\omega(\lambda, z)$ and $g(\lambda, \theta, z)$ may lead to more substantial errors.

\subsection{Use of the empirical aerosol model for calculating the solar radiative fluxes}

An example demonstrating the empirical aerosol model in simulating broadband fluxes is presented in this section. The aerosol radiative parameters were calculated using the exact refractive index and size distribution obtained from this model. The calculations of instantaneous solar radiation fluxes were performed using average summer parameters of the atmosphere over West Siberia within the time interval $T_{1} \leq t \leq T_{2}$, where $T_{1}$ and $T_{2}$ correspond to the sunrise and sunset times on July 15 for the latitude of Tomsk $\left(56^{\circ} \mathrm{N}\right)$.

To obtain a complete set of the input parameters for the simulation, the empirical model was complemented as follows:

- the optical characteristics in the altitude interval of 5-35 $\mathrm{km}$ were taken from the OPAC model with a continental average $\mathrm{RH}$ of $70 \%$;

- the extinction coefficients were extrapolated to the wider range of $0.37-1.02 \mu \mathrm{m}$ using the Ångström exponent $\alpha(0.44-0.87 \mu \mathrm{m})$, and outside the interval of $0.37-$ $1.02 \mu \mathrm{m}$, the extinction coefficients were assumed to be constant and equal to the respective boundary values for $\lambda=0.37 \mu \mathrm{m}$ and $\lambda=1.02 \mu \mathrm{m}$;

- the scattering phase functions and single scattering albedos of aerosol outside the interval of $0.44-0.87 \mu \mathrm{m}$ were assumed to be constant and equal to the respective boundary values for $\lambda=0.44 \mu \mathrm{m}$ and $\lambda=0.87 \mu \mathrm{m}$.

We used this approach because the Ångström exponents $\alpha$ $(0.37-1.02 \mu \mathrm{m})$ determined according to the airborne and AERONET measurements are comparable. Secondly, neglecting the spectral dependences of the scattering phase

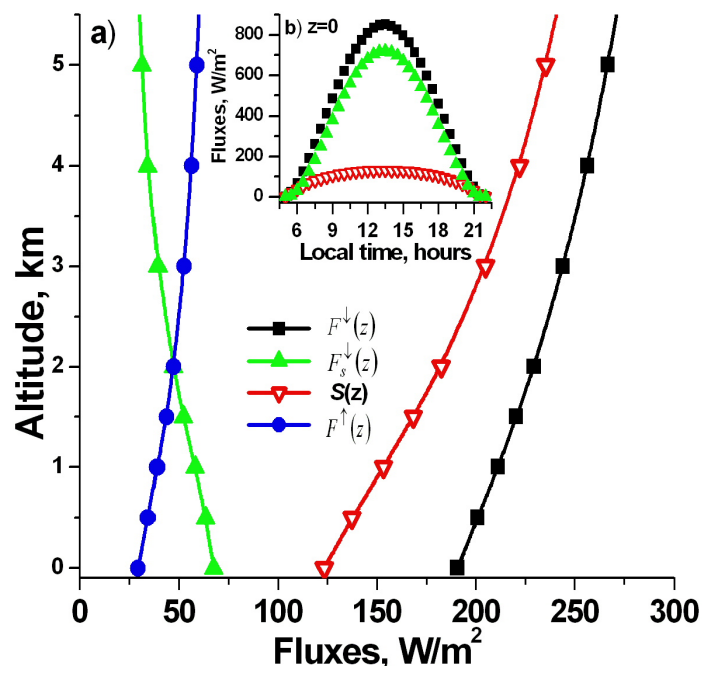

Fig. 6. Vertical profiles of the solar radiative fluxes calculated using our empirical model at 07:00 LT on 15 July $\left(\mathrm{SZA}=75.618^{\circ}\right)$ (a) and time variations in the downward radiation fluxes at the surface level $(\mathbf{b}) ; \tau_{\mathrm{a}}(0.5 \mu \mathrm{m})=0.16$.

function and single scattering albedo does not significantly affect the solar radiative fluxes (Sect. 3.1).

The vertical profiles of upward and downward radiative fluxes in the altitude range of $0 \leq z \leq 5 \mathrm{~km}$ at $\mathrm{SZA}=75.62^{\circ}$ (07:00 a.m. LT - local time) are presented in Fig. 6a. The instantaneous values of the downward radiative fluxes at the underlying surface level as a function of the solar zenith angle are shown in Fig. 6b. The daily average values of the shortwave component of the aerosol direct radiative effect (DRE) for the aforementioned input parameters are $(-15.1) \mathrm{W} \mathrm{m}^{-2}$ and $(-6.8) \mathrm{W} \mathrm{m}^{-2}$ at the bottom and top of the atmosphere, respectively.

We compared the obtained estimates with the DRE simulation results using three OPAC models of continental aerosol: clean, average and polluted (Hess et al., 1998). The wide range of variations in the single scattering albedo and asymmetry factor presented in these models makes it possible to describe a sufficiently large number of situations that can be observed in the atmosphere. Calculations of the daily average DRE values for $\tau_{\mathrm{a}}(0.5 \mu \mathrm{m})=0.16$ show that the range of the DRE for the three aforementioned models is $(-16.5)-$ $(-14.6) \mathrm{W} \mathrm{m}^{-2}$ and $(-7.8)-(-5.0) \mathrm{W} \mathrm{m}^{-2}$ at the bottom and top of the atmosphere, respectively.

The DRE estimates obtained using our empirical model and the OPAC continental aerosol model are in good agreement. At the same time, one should note that we compared the aerosol radiative effects only at the boundaries of the atmosphere. The majority of aerosol models and the data obtained by AERONET, in contrast to the model of the vertical profiles of aerosol characteristics, do not enable one to obtain data on changes in the upward and downward radiative fluxes 
inside the atmosphere and to more adequately estimate, for example, changes in the cooling rate.

\section{Discussion and conclusions}

On the basis of our empirical model, we performed a series of numerical experiments to obtain preliminary estimates of the direct radiative effect for typical summer conditions in Western Siberia. Here, we briefly discuss some aspects of this approach.

Firstly, this model (Panchenko et al., 1998; Panchenko and Terpugova, 2002), developed on the basis of airborne sensing, provides for the retrieval of vertical profiles of aerosol parameters under different conditions. In particular, knowledge of the air mass type and time of day (night, morning, day or evening) and the availability of data on near-ground values of the scattering coefficient, temperature and relative humidity of air make it possible to more reliably estimate the sought aerosol parameters. In the case that data on the aerosol optical depth and/or lidar vertical profiles are available, one can essentially reduce the errors in retrieving, which are characteristic of all statistical models.

However, the main purpose of this paper was to validate this technique for the application of experimental data in the development of an empirical model of optical characteristics, which are needed for radiative calculations. Thus, at this stage, we considered only the average summer values of the measured parameters, and the data were not divided into subarrays corresponding to absolutely cloudless sky and few-cloud situations.

Secondly, when calculating the refractive indices, we used the mixture rule; hence, we a priori assumed that the absorbing substance exists as an "internal mixture" in the aerosol particles. In our opinion, this assumption is justified because, according to literature data (see, for example, Bond and Bergstrom, 2006), there are reasons to assume that BC exists in aerosol as an "external mixture" only in the early phase of its emission, i.e., in the regions next to the actual sources of hydrocarbon material burning. The state of an internal mixture of aerosol and $\mathrm{BC}$ is realised in the process of the long-range transport of air masses during aerosol "ageing". It is important to note that all of our measurements in the atmosphere of West Siberia were carried out in background regions far from large industrial centres.

The next problem under discussion is related to our choice of the $\mathrm{BC}$ concentration ratio for submicron and coarse particles. Our photoacoustic measurements of the spectral dependences of the aerosol light absorption in the near-ground layer of the atmosphere Tikhomirov et al. (2005) showed, with high accuracy, that this dependence is close to $\sim \lambda^{-1}$, providing evidence of the fact that the main portion of absorbing substance is localised in particles smaller than visible wavelengths. At the same time, by assuming the ratio of $\mathrm{BC}$ content to be $90 \%$ in the submicron fraction and $10 \%$ in the coarse one, we followed the data of Gelencser (2004), Hitzenberger and Tohno, (2001), Kozlov et al. (2002), Höler et al., (2002) and Delene and Ogren (2002). Taking into account the methodical remarks, let us note that the main assumptions introduced into the scheme of the model construction do not contradict data from numerous measurements of atmospheric aerosol properties.

The obtained model of the vertical profiles of the aerosol optical characteristics was used to calculate the broadband solar radiative fluxes and the aerosol direct radiative effect. At this stage, we did not seek to thoroughly study the radiative effects of aerosol under specific atmospheric conditions over West Siberia; rather, we used only the average values of the optical characteristics. Our main efforts were concentrated on estimating the capabilities of the model from the standpoint of its application to radiative calculations and on determining areas for improvement.

The testing of the developed empirical model on the basis of the average values of the measured and retrieved parameters for calculating the solar radiative fluxes provides evidence that the vertical profiles of the aerosol optical characteristics will allow one to obtain more precise estimates of the radiative parameters (in particular, the rates of cooling and solar radiation absorption) within the troposphere. We assume that the development of an empirical model can be achieved through a more detailed account of the size distribution of absorbing materials as well as through a comparison of the retrieved optical properties for specific atmospheric situations and the results of lidar and photometric measurements. The application of the described approach to interpreting the results of closure radiation experiments under specific atmospheric conditions will aid in the development and improvement of both the empirical model and computer codes for radiative calculations.

Acknowledgements. This work was supported in part by Programme 12.2 of the Department of Earth Sciences, the Russian Academy of Sciences, the Russian Foundation for Basic Research (grants No. 10-05-00162 and 11-05-93119), and by state contracts 02.740.11.0674 and 14.740.11.0204.

Edited by: A. Kokhanovsky

\section{References}

Albrecht, B.: Aerosols, cloud microphysics, and fractional cloudiness, Science, 245, 1227-1230, 1989.

Anderson, G., Clough, S., Kneizys, F., Chetwynd, J., and Shettle, E.: AFGL Atmospheric Constituent Profiles (0-120 km), Air Force Geophysics Laboratory, AFGL-TR-86-0110, Environmental Research Paper, N 954, 1986.

Anderson, T. L., Masonis, S. J., Covert, D. S., Ahlquist, N. C., Howell, S. G., Clarke, A. D., and McNaughton, C. S.: Variability of aerosol optical properties derived from in situ aircraft 
measurements during ACE Asia, J. Geophys. Res., 108, 8647, doi:10.1029/2002JD003247, 2003.

Andrews, E., Sheridan, P. J., and Ogren, J. A.: Seasonal differences in the vertical profiles of aerosol optical properties over rural Oklahoma, Atmos. Chem. Phys., 11, 10661-10676, doi:10.5194/acp-11-10661-2011, 2011.

Arshinov, M. Yu., Belan, B. D., Davydov, D. K., Inouye, G., Maksyutov, Sh., Machida, T., and Fofonov, A. V.: Vertical distribution of greenhouse gases above Western Siberia by the longterm measurement data, Atmos. Ocean. Opt., 22, 316-324, 2009.

Bedareva, T. V. and Zhuravleva, T. B.: Retrieval of aerosol scattering phase function and single scattering albedo according to data of radiation measurements in solar almucantar: numerical simulation, Atmos. Ocean. Opt., 24, 373-385, 2011.

Bedareva, T. V. and Zhuravleva, T. B.: Estimation of Aerosol Absorption under Summer Conditions of Western Siberia from Sun Photometer Data, Atmos. Ocean. Opt., 25, 216-223, 2012.

Bond, T. C. and Bergstrom, R. W.: Light absorption by carbonaceous particles: an investigative review, Aerosol Sci. Tech., 40, 27-67, 2006.

Brock, C. A., Cozic, J., Bahreini, R., Froyd, K. D., Middlebrook, A. M., McComiskey, A., Brioude, J., Cooper, O. R., Stohl, A., Aikin, K. C., de Gouw, J. A., Fahey, D. W., Ferrare, R. A., Gao, R.-S., Gore, W., Holloway, J. S., Hübler, G., Jefferson, A., Lack, D. A., Lance, S., Moore, R. H., Murphy, D. M., Nenes, A., Novelli, P. C., Nowak, J. B., Ogren, J. A., Peischl, J., Pierce, R. B., Pilewskie, P., Quinn, P. K., Ryerson, T. B., Schmidt, K. S., Schwarz, J. P., Sodemann, H., Spackman, J. R., Stark, H., Thomson, D. S., Thornberry, T., Veres, P., Watts, L. A., Warneke, C., and Wollny, A. G.: Characteristics, sources, and transport of aerosols measured in spring 2008 during the aerosol, radiation, and cloud processes affecting Arctic Climate (ARCPAC) Project, Atmos. Chem. Phys., 11, 2423-2453, doi:10.5194/acp-11-24232011, 2011.

Chesnokova, T. Yu., Voronin, B. A., Bykov, A. D., Zhuravleva, T. B., Kozodoev, A. V., Lugovskoy, A. A., and Tennyson, J.: Calculation of solar radiation atmospheric absorption with different $\mathrm{H}_{2} \mathrm{O}$ spectral line data banks, J. Mol. Spectrosc., 256, 41-44, 2009.

Clarke, A. and Kapustin, V.: Hemispheric Aerosol Vertical Profiles: Anthropogenic Impacts on Optical Depth and Cloud Nuclei, Science, 329, 1488-1492, 2010.

Clough, S. A., Shephard, M. W., Mlawer, E. J., Delamere, J. S., Iacono, M. J., Cady-Pereira, K., Boukabara, S., and Brown, P. D.: Atmospheric radiative transfer modeling: A summary of the AER codes, J. Quant. Spectrosc. Ra., 91, 233-244, 2004.

Collins, D. R., Jonsson, H. H., Seinfeld, J. H., Flagan, R. C., Gassio, S., Hegg, D. A., Russell, P. B., Schmid, B., Livingston, J. M., Ostrom, E., Noone, K. J., Russell, L. M., and Putaud, J. P.: In situ aerosol size distributions and clear column radiative closure during ACE-2, Tellus B, 52, 498-525, 2000a.

Collins, D. R., Jonsson, H. H., Liao, H., Flagan, R. C., Seinfeld, J. H., Noone, K. J., and Hering, S. V.: Airborne analysis of the Los Angeles aerosol, Atmos. Environ., 34, 4155-4173, 2000b.

De Reuss, M., Krejci, R., Williams, J., Fischer, H., Scheele, R., and Strom, J.: Vertical and horizontal distributions of the aerosol number concentration and size distribution over the northern Indian Ocean, J. Geophys. Res., 106, 28629-28641, 2001.
Delene, D. J. and Ogren, J. A.: Variability of aerosol optical properties at four North American surface monitoring sites, J. Atmos. Sci., 59, 1135-1150, 2002.

Dubovik, O. T. and King, M. A.: Flexible inversion algorithm for retrieval aerosol optical properties from Sun and sky radiance measurements, J. Gephys. Res., 105, 20673-20696, 2000.

Fontenla, J., White, O. R., Fox, P. A., Avert, E. H., and Kurucz, R. L.: Calculation of solar irradiances, I. Synthesis of the solar spectrum, Astrophys. J., 518, 480-500, 1999.

Firsov, K. M. and Chesnokova, T. Yu.: A new method of treating overlapping absorption bands of atmospheric gases in radiative transfer parameterization, Atmos. Ocean. Opt., 11, 356-360, 1998.

Fuchs, N. A.: The Mechanics of Aerosols, Pergamon, Oxford, 1964. García, O. E., Díaz, J. P., Expósito, F. J., Díaz, A. M., Dubovik, O., Derimian, Y., Dubuisson, P., and Roger, J.-C.: Shortwave radiative forcing and efficiency of key aerosol types using AERONET data, Atmos. Chem. Phys., 12, 5129-5145, doi:10.5194/acp-125129-2012, 2012.

Gelencser, A.: Carbonaceous aerosol, Springer, Dordrecht, The Netherlands, 2004.

Green, H. L, and Lane, W. H.: Particulate Clouds: Dusts, Smokes, and Mists, Spon Ltd., London, 1964.

Han, Z., Montague, D. C., and Snider, J. R.: Airborne measurements of aerosol extinction in the lower and middle troposphere over Wyoming, USA, Atmos. Environ., 37, 789-902, 2003.

Hanel, G.: The properties of atmospheric aerosol particles as function of relative humidity at the thermodynamic equilibrium with surrounding moist air, Adv. Geophys., 19, 73-188, 1976.

Hartley, W. S., Hobbs, P. V., Ross, J. L., Russell, P. B., and Livingston, J. M.: Properties of aerosols aloft relevant to direct radiative forcing off the mid-Atlantic coast of the United States, J. Geophys. Res., 105, 9859-9885, 2000.

Haywood, J. and Boucher, O.: Estimates of the direct and indirect radiative forcing due to tropospheric aerosols: A review, Rev. Geophys., 38, 513-543, 2000.

Hegg, D. A., Livingston, J., Hobbs, P. V., Novakov, T., and Russell, P.: Chemical apportionment of aerosol column optical depth off the mid-Atlantic coast of the United States, J. Geophys. Res., 102, 25293-25303, 1997.

Hess, M., Koepke, P., and Schult, I.: Optical properties of aerosols and clouds: The software package OPAC, B. Am. Meteorol. Soc., 79, 831-844, 1998.

Hitzenberger, R. and Tohno, S.: Comparison of black carbon (BC) aerosols in two urban areas - concentrations and size distributions, Atmos. Environ., 35, 2153-2167, 2001.

Höler, R., Tohno, S., Kasahara, M., and Hitzenberger, R.: Longterm characterization of carboneous aerosol in Uji, Japan, Atmos. Environ., 36, 1267-1275, 2002.

IPCC - Intergovernmental Panel on Climate Change: Climate Change 2007: The Physical Science Basis, Contribution of Working Group I to the Fourth Assessment Report of the Intergovernmental Panel on Climate Change, Cambridge, UK and New York, NY, USA, 2007.

Ivlev, L. S.: Aerosol forcing in climate processes, Atmos. Ocean. Opt., 24, 392-410, 2011.

Johnson, B., Shine, K., and Forster, P.: The semi-direct aerosol effect: Impact of absorping aerosols on marine stratocumulus, Q. J. Roy. Meteorol. Soc., 130, 1407-1422, 2004. 
Johnson, B. T., Heese, B., McFarlane, S. A., Chazette, P., Jones, A., and Bellouin, N.: Vertical distribution and radiative effects of mineral dust and biomass burning aerosol over West Africa during DABEX, J. Geophys. Res., 113, D00C12, doi:10.1029/2008JD009848, 2008.

Kabanov, M. V., Panchenko, M. V., Pkhalagov, Yu. A., Veretennikov, V. V., Uzhegov, V. N., and Fadeev, V. Ya.: Optical properties of coastal atmospheric hazes, Nauka, Novosibirsk, 1988.

Komarov, V. S. and Lomakina, N. Ya.: Statistical models of the atmospheric boundary layer, IAO Publishing House, Tomsk, 2008.

Koshinskii, S. D., Trifonova, L. I., and Shver, T. A.: Climate of Tomsk, Gidrometeoizdat, Leningrad, 1982.

Kozlov, V. S., Panchenko, M. V., Kozlov, A. S., Ankilov, A. N., Baklanov, A. M., and Malyshkin, S. B.: Instrumental and Technical Approach to Prompt Field Measurements of Size Distributions of Aerosol Absorbing and Scattering Characteristics, in: Proceedings of the Twelfth Atmospheric Radiation Measurement (ARM) Science Team Meeting, http://www.arm.gov/publications/proceedings/conf12/ extended_abs/kozlov2-vs.pdf?id=40, last access: June 2012, St. Petersburg, Florida, 2002.

Kozlov, V. S., Panchenko, M. V., and Yausheva, E. P.: Time content variations of submicrometer aerosol and soot in the near-ground layer of the West Siberia atmosphere, Atmos. Ocean. Opt., 20, 987-990, 2007.

Kozlov, V. S. Panchenko, M. V., and Yausheva, E. P.: Mass fraction of Black Carbon in submicrometer aerosol as an indicator of influence of smokes from remote forest fires in Siberia, Atmos. Environ., 42, 2611-2620, 2008.

Kozlov, V. S., Shmargunov, V. P., and Panchenko, M. V.: Seasonal variability of the vertical profiles of absorption parameters of submicrometer aerosol in the troposphere, Atmos. Ocean. Opt., 22, 635-642, 2009.

Lacis, A. A. and Oinas, V.: A description of the $k$-distribution method for modelling nongray gaseous absorption, thermal emission, and multiple scattering in vertically inhomogeneous atmospheres, J. Geophys. Res., 96, 9027-9063, 1991.

Magi, B. I., Hobbs, P. V., Schmid, B., and Redemann, J.: Vertical profiles of light scattering, light absorption, and single scattering albedo during the dry, biomass burning season in southern Africa and comparisons of in situ and remote sensing measurements of aerosol optical depths, J. Geophys. Res., 108, 8504, doi:10.1029/2002JD002361, 2003.

Magi, B.I ., Hobbs, P. V., Kirchstetter, T. W., Novakov, T., Dean, A., Hegg, D. A., Gao, S., Redemann, J., and Schmid, B.: Aerosol Properties and Chemical Apportionment of Aerosol Optical Depth at Locations off the U.S. East Coast in July and August 2001, J. Atmos. Sci., 62, 919-933, 2005.

Mayer, B. and Kylling, A.: Technical note: The libRadtran software package for radiative transfer calculations - description and examples of use, Atmos. Chem. Phys., 5, 1855-1877, doi:10.5194/acp-5-1855-2005, 2005.

McNaughton, C. S., Clarke, A. D., Freitag, S., Kapustin, V. N., Kondo, Y., Moteki, N., Sahu, L., Takegawa, N., Schwarz, J. P., Spackman, J. R., Watts, L., Diskin, G., Podolske, J., Holloway, J. S., Wisthaler, A., Mikoviny, T., de Gouw, J., Warneke, C., Jimenez, J., Cubison, M., Howell, S. G., Middlebrook, A., Bahreini, R., Anderson, B. E., Winstead, E., Thornhill, K. L., Lack, D., Cozic, J., and Brock, C. A.: Absorbing aerosol in the troposphere of the Western Arctic during the 2008 ARCTAS/ARCPAC airborne field campaigns, Atmos. Chem. Phys., 11, 7561-7582, doi:10.5194/acp-11-7561-2011, 2011.

Moody, E. G., King, M. D., Platnick, S., Schaaf, C. B., and Gao, F.: Spatially compete global spectral surface albedos: value-added datasets derived from Terra MODIS Land products, IEEE T. Geosci. Remote, 43, 144-158, 2005.

O'Hirok, W. and Gautier, C.: A Three-Dimensional Radiative Transfer Model to Investigate the Solar Radiation within a Cloudy Atmosphere, Part I: Spatial Effects, J. Atmos. Sci., 55, 2162-2179, 1998.

Osborne, S. R. and Haywood, J. M.: Aircraft observations of the microphysical and optical properties of major aerosol species, Atmos. Res., 73, 173-201, 2005.

Öström, E. and Noone, K. J.: Vertical profiles of aerosol scattering and absorption measured in situ during the North Atlantic Aerosol Characterization Experiment (ACE-2), Tellus B, 52, 526-545, 2000.

Panchenko, M. V. and Terpugova, S. A.: Reconstruction of the scattering coefficient in the lower troposphere using ground-based measurement, J. Atmos. Sci., 59, 581-589, 2002.

Panchenko, M. V., Terpugova, S. A., and Tumakov, A. G.: Annual variations of submicrometer aerosol fraction as assessed from the data of airborne nephelometric measurements, Atmos. Res., 41, 203-215, 1996.

Panchenko, M. V., Terpugova, S. A., and Pol'kin, V. V.: Empirical model of the aerosol optical properties in the troposphere over West Siberia, Atmos. Ocean. Opt., 11, 532-539, 1998.

Panchenko, M. V., Kozlov, V. S., Terpugova, S. A., Shmargunov, V. P., and Burkov, V. V.: Simultaneous measurements of submicrometer aerosol and absorbing substance in the altitude range up to $7 \mathrm{~km}$, in: Proceedings of Tenth ARM Science Team Meeting, http://www.arm.gov/publications/proceedings/conf10/ extended_abs/panchenko_mv.pdf?id=85, last access: June 2012, San-Antonio, Texas, 2000.

Panchenko, M. V., Sviridenkov, M. A., Terpugova, S. A., and Kozlov, V. S.: Active spectral nephelometry as a method for the study of submicrometer atmospheric aerosols, Atmos. Ocean. Opt., 17, 378-386, 2004.

Panchenko, M. V., Terpugova, S. A., Kozlov, V. S., Pol'kin, V. V., and Yausheva, E. P.: Annual behavior of the condensation activity of submicrometer aerosol in the atmospheric surface layer of Western Siberia, Atmos. Ocean. Opt., 18, 607-611, 2005.

Redemann, J., Masonis, S. J., Schmid, B., Anderson, T. L., Russell, P. B., Livingston, J. M., Dubovik, O., and Clarke, A. D.: Clearcolumn closure studies of aerosols and water vapor aboard the NCAR C-130 during ACE-Asia, 2001, J. Geophys. Res., 108, 8655, doi:10.1029/2003JD003442, 2003.

Ricchiazzi, P., Yang, S., Gautier, C., and Sowle, D.: SBDART: A research and teaching software tool for plane-parallel radiative transfer in the Earth's atmosphere, B. Am. Meteorol. Soc., 79, 2101-2114, 1998.

Sakerin, S. M. and Kabanov, D. M.: Spectral dependence of the atmosphere aerosol optical depth near 0.37-4 $\mu \mathrm{m}$, Atmos. Ocean. Opt., 20, 141-149, 2007.

Sakerin, S. M., Smirnov, A., Kabanov, D. M., Pol'kin, V. V., Panchenko, M. V., Holben, B. N., and Kopelevich, O. V.: Aerosol optical and microphysical properties over the Atlantic Ocean during the 19th cruise of the Research Vessel 
“Akademik Sergey Vavilov”, J. Geophys. Res., 112, D10220, doi:10.1029/2006JD007947, 2007.

Sakerin, S. M., Beresnev, S. A., Gorda, S. Yu., Kabanov, D. M., Kornienko, G. I., Markelov, Yu. I., Mikhalev, A. V., Nikolashkin, S. V., Panchenko, M. V., Poddubnyi, V. A., Pol'kin, V. V., Smirnov, A. V., Tashilin, M. A., Turchinovich, S. A., Turchinovich, Yu. S., Holben, B., and Eremina, T. A.: Characteristics of annual behavior of spectral aerosol optical depth of the atmosphere under conditions of Siberia, Atmos. Ocean. Opt., 22, 446-456, 2009.

Schwarz, J. P., Gao, R. S., Fahey, D. W., Thomson, D. S., Watts, L. A., Wilson, J. C., Reeves, J. M., Darbeheshti, M., Baumgardner, D. G., Kok, G. L., Chung, S. H., Schulz, M., Hendricks, J., Lauer, A., Karcher, B., Slowik, J. G., Rosenlof, K. H., Thompson, T. L., Langford, A., Loewenstein, M., and Aikin, K. C.: Single-particle measurements of midlatitude black carbon and light-scattering aerosols from the boundary layer to the lower stratosphere, J. Geophys. Res., 111, D16207, doi:10.1029/2006JD007076, 2006.

Shinozuka, Y., Clarke, A. D., Howell, S. G., Kapustin, V. N., McNaughton, C. S., Zhou, J., and Anderson, B. E.: Aircraft profiles of aerosol microphysics and optical properties over North America: Aerosol optical depth and its association with $\mathrm{PM}_{2.5}$ and water uptake, J. Geophys. Res., 112, D12S20, doi:10.1029/2006JD007918, 2007.

Slingo, A.: A GCM parameterization for shortwave radiative properties of water clouds, J. Atmos. Sci., 46, 1419-1427, 1989.

Takemura, T., Nakajima, T., Dubovik, O., Holben, B., and Kinne, S.: Single-scattering albedo and radiative forcing of various aerosol species with a global three-dimensional model, J. Climate, 15, 333-352, 2002.

Taubman, B. F., Hains, J. C., Thompson, A. M., Marufu, L. T., Doddridge, B. G., Stehr, J. W., Piety, C. A., and Dickerson, R. R.: Aircraft vertical profiles of trace gas and aerosol pollution over the mid-Atlantic United States: Statistics and meteorological cluster analysis, J. Geophys. Res., 111, D10S07, doi:10.1029/2005JD006196, 2006.

Terpugova, S. A., Panchenko, M. V., and Kozlov, V. S.: Estimation of the effect of black carbon on the single scattering albedo of submicrometer aerosol, in: Abstracts of European Aerosol Conference, 28 August-2 September, Ghent, Belgium, 704, 2005.
Tikhomirov, A. B., Firsov, K. M., Kozlov, V. S., Panchenko, M. V., Ponomarev, Y. N., and Tikhomirov, B. A.: Investigation of spectral dependence of shortwave radiation absorption by ambient aerosol using time-resolved photoacoustic technique, Opt. Eng., 071203, 1-11, 2005.

Tvorogov, S. D., Zhuravleva, T. B., Rodimova, O. B., and Firsov, K. M.: Theory of series of exponents and its application for analysis of radiation processes, in: Problems of Global Climatology and Ecodynamics: Anthropogenic Effects on the State of Planet Earth, edited by: Cracknell, A. P., Krapivin, V. F., and Varotsos, C. A., Springer/Praxis, Chichester, UK, 211-240, 2008.

Twomey S. The influence of pollution on the shortwave albedo of clouds, J. Atmos. Sci., 34, 1149-1152, 1977.

Varotsos, C.: Airborne measurements of aerosol, ozone, and solar ultraviolet irradiance in the troposphere, J. Geophys. Res., 110, D09202, doi:10.1029/2004JD005397, 2005.

Yu, H., Kaufman, Y. J., Chin, M., Feingold, G., Remer, L. A., Anderson, T. L., Balkanski, Y., Bellouin, N., Boucher, O., Christopher, S., DeCola, P., Kahn, R., Koch, D., Loeb, N., Reddy, M. S., Schulz, M., Takemura, T., and Zhou, M.: A review of measurement-based assessments of the aerosol direct radiative effect and forcing, Atmos. Chem. Phys., 6, 613-666, doi:10.5194/acp-6-613-2006, 2006.

Zhou, M., Yu, H., Dickinson, R., Dubovik, O., and Holben, B.: A normalized description of the direct effect of key aerosol types on solar radiation as estimated from AERONET aerosols and MODIS albedo, J. Geophys. Res., 110, D19202, doi:10.1029/2005JD005909, 2006.

Zhuravleva, T. B.: Simulation of solar radiative transfer under different atmospheric conditions, PartI: Deterministic atmosphere, Atmos. Ocean. Opt., 21, 99-114, 2008.

Zhuravleva, T. B., Kabanov, D. M., Sakerin, S. M., and Firsov, K. M.: Simulation of direct aerosol radiative forcing for typical summer conditions of Siberia, Part 1: Method of calculation and choice of the input parameters, Atmos. Ocean. Opt., 22, 63-73, 2009. 